


\section{Crepes \& Waffles: Una filosofía del talento humano puesta en marcha}

ESUMEN

Este artículo describe la receta gerencial que ha Ilevado al éxito a Crepes \& Waffles, una de las empresas más importantes del sector del servicios de alimentos del país: una muy especial concepción de la gerencia de recursos humanos basada en cuatro principios fundamentales: paz, amor, armonía $y$ felicidad.

\section{palabras clave}

Gerencia de recursos humanos, valores, servicios de alimentos

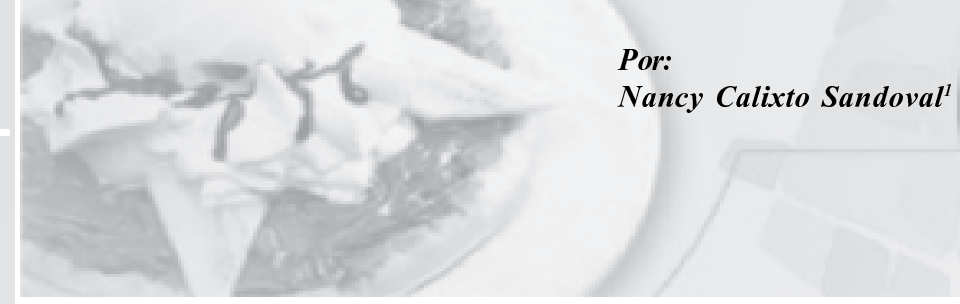

¡Placer que genera placer! iServir amor traducido en alimento!

Nos hemos propuesto servir arte, con amor y alegria; inspirar en nuestros clientes frases como "comida de dioses servida por ángeles», conquistar corazones y cautivar paladares; ser promotores de miel encuentros; cómplices de versos y canciones; queremos llegar al que está triste, alimentar al que llega hambriento y seducir al goloso.

Como compañia, generamos el conocimiento y la admiración, el amor

el amor, la alegría y una visión individual de progreso.

Lideramos nuestras misiones con un gran corazón y sentido de responsabilidad social, conscientes de que las empresas son sostenibles, siempre y cuando ayuden a satisfacer las necesidades de sus trabajadores y de su sociedad.

Beatriz Fernández, socia de Crepes \& Waffles

\footnotetext{
1 Nancy Calixto Sandoval. Docente investigadora de la Universidad EAN. Ejecutiva entrevistada: Beatriz Fernández. Socia y Gerente de Recursos Humanos de Crepes \& Waffles.
} 
La gestión gerencial se desarrolla en las organizaciones mediante diversas estratégicas basadas en filosofías más o menos tradicionales. En este último grupo se encuentran las organizaciones que sustentan sus políticas gerenciales en teorías y aspectos netamente humanistas cuyo pilar fundamental son los valores y principios universales con un único objetivo: hacer más competitivas las organizaciones de tal manera que no solo sobrevivan en un mercado cada vez más exigente sino que logren posiciones que las distingan como empresas de talla mundial.

Es importante puntualizar que las políticas son enunciados o interpretaciones generales que orientan el pensamiento de los administradores en la toma de decisiones; su propósito es asegurar que las decisiones no rebasen ciertos límites. Por su parte las estrategias se refieren a la dirección en que se encauzan recursos a fin de acrecentar la posibilidad de cumplir con los objetivos.

En relación a la labor específica que se desarrolla desde el área de la gestión humana es claro que ésta implica atraer, desarrollar y mantener una fuerza laboral talentosa y llena de energía para apoyar la misión y la visión organizacionales, con el fin de alcanzar los objetivos de posicionamiento dentro del mercado. Con el fin que las estrategias corporativas se implementen adecuadamente se requiere de trabajadores con compromiso y entusiasmo evidente. La labor de la administración estratégica del talento humano consiste en conseguir de los colaboradores tales actitudes positivas.

Según la opinión de importantes autores e investigadores acerca de la administración contemporánea entre quienes se encuentra Schermerhorn ${ }^{2}$, los gerentes contemporáneos deben aceptar y responder positivamente a los retos complejos de un mundo en transformación encontrando buscando como característica fundamental

2 El doctor Schermenrthorn obtuvo el grado de Ph.D. en comportamiento organizacional por la Northwestern University, la maestría en administración y negocios internacionales por la Universidad de Nueva York. Ha trabajado en China, Egipto, Indonesia, Malasia, Venezuela y Tanzania. Se desempeñó como presidente de la división de educación y desarrollo de administración de la Academy of Management.

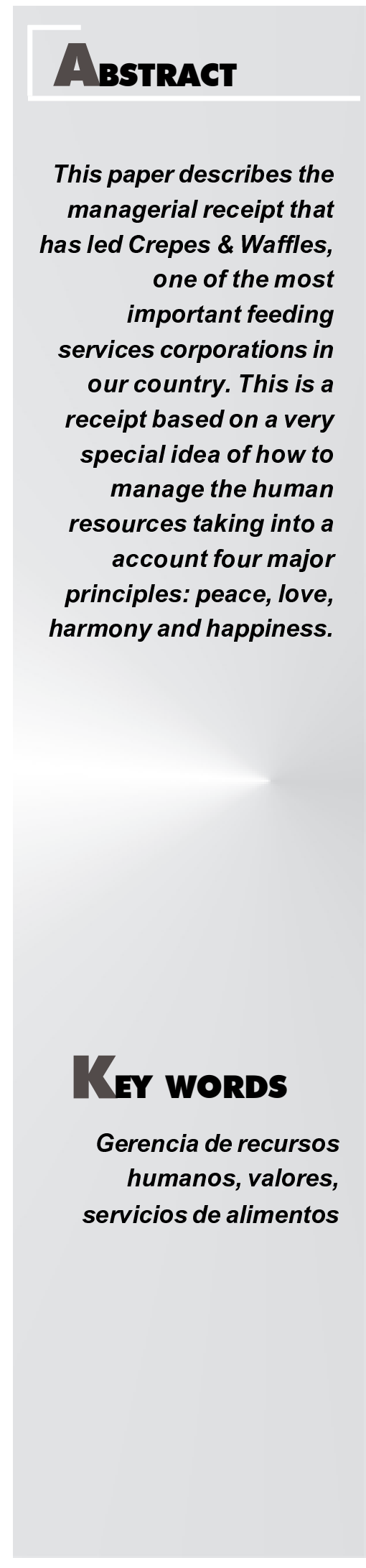


del administrador el liderazgo motivador; en otras palabras la capacidad del empresario para estimular a sus trabajadores propiciando un alto nivel de motivación, generando un excelente clima organizacional que conduzca a un desempeño eficiente para el trabajo en equipos.

Beatriz Fernández, propietaria y cofundadora de Crepes \& Waffles, ha generado una innovadora cultura organizacional a partir de un nuevo estilo de gerencia. Desde hace 25 años Crepes \& Waffles ha venido trabajando por la consolidación, el posicionamiento y la competitividad de la empresa mundial, no solo a nivel nacional sino también internacional y ha establecido en el mercado un estilo de vida y una sensación de compra única y exportable.

\section{Una empresa en donde el amor es la principal estrategia de gestión}

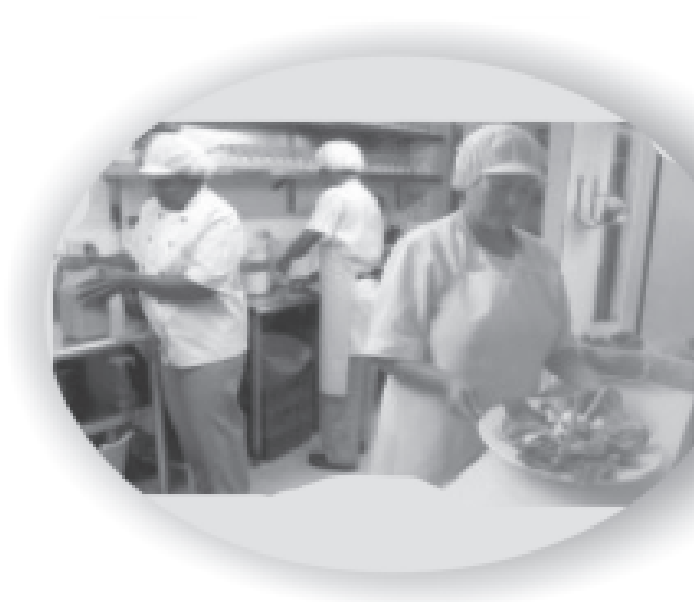

El prestigio y liderazgo de Crepes \& Waffles en el sector de servicios de alimentos es ampliamente conocido. Esta empresa tuvo sus orígenes hace 25 años un 13 de mayo, cuando dos jóvenes, Beatriz Fernández y Eduardo Macías, estudiaban administración de empresas y decidieron abrir un pequeño local de venta de crepes en donde se ofrecían apenas tres de los productos hoy en día líderes en un extenso menú.

Esta empresa cuenta actualmente con varias sucursales en las ciudades más importantes de Colombia. A nivel internacional está ubicada en Ecuador, Venezuela, Panamá, México y España. La organización cuenta con alrededor de 1.700 empleados en su nómina, constituida en su gran mayoría por mujeres, madres cabeza de hogar.

Beatriz trasmite la filosofía empresarial día a día a todas y cada uno de las personas que trabajan en sus restaurantes. Este ha sido un ejercicio administrativo que ha venido implementando en la compañía casi desde sus inicios. Además de ser innovadora en los productos y en la forma de presentarlos a sus clientes, agrega a la fórmula una gran dosis de espiritualidad. La propietaria declara expresamente que la espiritualidad se manifiesta en un profundo contenido de la palabra amor.

Como dice ella, el amor es luz, es vida, es creatividad, es armonía; es potencializar todos los talentos para ponerlos al servicio de los demás. En un ambiente donde hay amor, las dificultades se vuelven un reto para todos. Vencer los obstáculos es una meta 
compartida por todos; formar un equipo consciente de la excelencia y de ser mejores personas para contribuir a generar un mejor país se vuelve un desafío compartido por todos los miembros de la organización.

El amor está presente en la empresa desde su creación y fundamenta su filosofía administrativa. Por eso Beatriz trasmite a sus empleadas el amor por Dios, pues concibe que Él es la luz de la vida y quien hace posible todo cuanto acontece en la empresa y en la vida en general de cada una de las personas.

Mientras la sociedad refleja actualmente una evidente crisis de valores que tiende a privilegiar la competencia sobre la cooperación, el consumismo sobre el uso racional de los recursos económicos y naturales, y la burocratización sobre una auténtica relación humana, en Crepes \& Waffles se estimula el desarrollo de los valores humanos no solo en el ámbito laboral, sino también a familiar y en especial en la relación entre madres e hijos. Esta política de gestión humana potencia al grupo de personas que laboran en Crepes y revierte a la sociedad no sólo mejor producción sino una mejor calidad de vida. En palabras de Beatriz: «Se necesita construir país.» Para esto se debe estimular a las empleadas, llenarlas de valores y motivos. Esto hace parte de la responsabilidad social de la organización.

La teoría de gestión de las organizaciones señala que la orientación ética es fundamental para cualquier empresa, puesto que orienta el comportamiento de los integrantes (empleados, ejecutivos, socios) hacia el logro de las metas y hacia la proyección social.
En este sentido los ejecutivos cumplen un papel muy importante en la creación y en el manteni-miento de la filosofía empresarial que la organización decida impulsar.

Como comenta Cullen², es claro que la orientación ética es muy importante para cualquier cultura organizacional. Los estándares éticos orientan la conducta de los integrantes de la organización. En este sentido y tal como se evidencia en la gestión de Beatriz Fernández, los ejecutivos juegan un papel fundamental en la creación y mantenimiento de los estándares éticos que Crepes \& Waffles ha decidido impulsar.

Se observa que las organizaciones con un clima ético fuerte y positivo establecen expectativas claras para sus miembros. Minimizan las dudas acerca del quehacer en caso de presentarse dilemas y demuestran un alto nivel de compromiso con la organización.

Como resultado de este clima ético y positivo se puede ampliar enormemente el impacto de la cultura organizacional sobre el desempeño de los integrantes de la organización. Y es allí donde está fundamentado el éxito alcanzado por esta importante cadena de restaurantes.

Cuando se abordan temas empresariales, es obligatorio analizar el entorno. Hoy la violencia representa una amenaza que pone en juego la paz mundial y la delincuencia aumenta y genera inseguridad, temor e incertidumbre. Frente a esta circunstancias, Crepes \& Waffles promueve y estimula en el seno de la organización valores del trabajador y de su familia, con la fórmula PAAF: 2 Citado por Shermenrthorn en su articulo An ethical weather report: Assessing the Organitation's Ethical
Climate. 


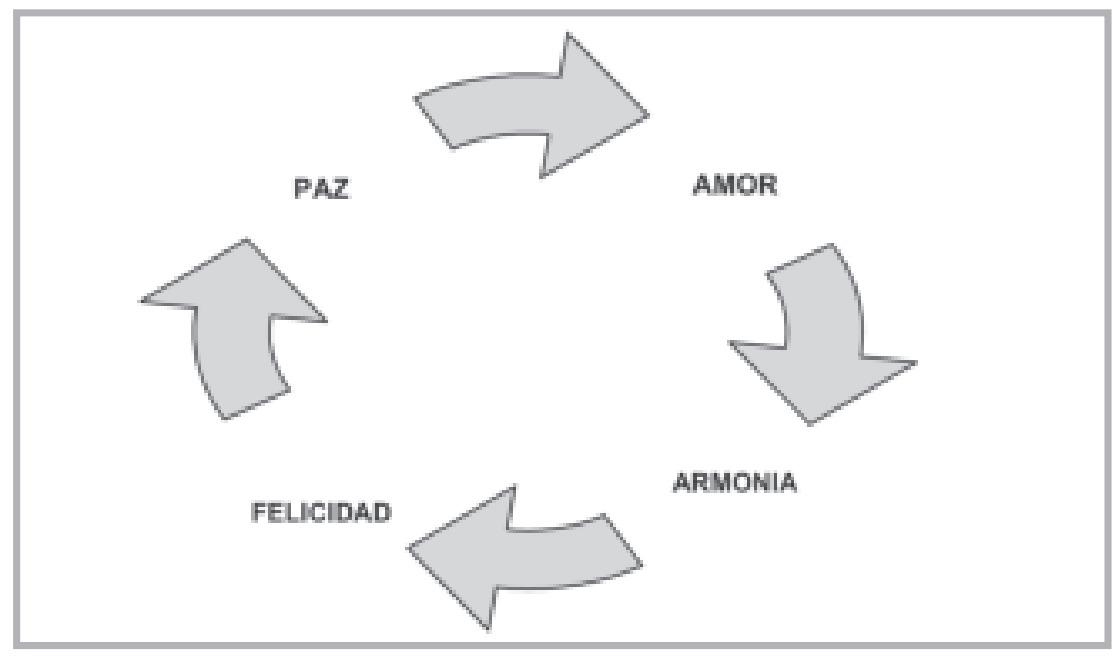

Como lo explica Beatriz, este gráfico identifica los cuatro pilares de su filosofía administrativa. A diario, mediante la tecnología de Avantel, se dirige a todas sus empleadas y les lee mensajes que transmiten: paz, amor, armonía y felicidad, con el objetivo de que estos mensajes trasciendan en su trabajo y en sus hogares.

El modelo de gestión humana utilizado por esta ejecutiva muestra una mezcla muy homogénea entre técnicas de la administración y recetas de cocina, pues en su estilo administrativo se evidencia el amor como ingrediente principal, esencia de su éxito empresarial, no sólo en los platos que ofrece a sus clientes sino también en la relación que mantiene con sus empleadas.

El enfoque gerencial en Crepes \& Waffles se basa en la necesidad de darle un sentido a lo que se hace. Es un enfoque netamente humanista, que busca la integración entre los intereses de los trabajadores y la de los fundadores. Es claro que no hay nada que se pueda lograr si no tiene un fundamento sólido y este fundamento, que a su vez orienta el quehacer tanto de directivos como de empleados, es el amor, entendido como la fuerza universal y primaria que orienta toda actividad humana. El amor permite identificar lo mejor que tiene cada uno y darlo a los demás: ésta es la esencia del servicio.

En la administración de esta empresa se refleja igualmente su posición frente problemas como la traición, el engaño, la trampa, la mentira y opone a estas conductas la verdad como orientadora de la vida y el trabajo. Esta es la única forma de dejar huella en el mundo y de agradar a los que se sirven, llámese cliente interno o externo.

Su gerencia estimula una filosofía basada en la toma de conciencia. Esta consiste en conectarse con la realidad y asumir compromisos de crecimiento. Si se supera la ignorancia y se distingue entre lo bueno y lo malo, es más difícil cometer errores o «ponerle zancadillas a la felicidad». Es aquí donde la gerencia estimula a los trabajadores a levantarse y a seguir como empresa trabajando y luchando juntos por el mismo sueño.

Hoy podemos criticar al ejercicio administrativo por no su falta de sensibilidad frente a las condiciones y los valores sociales de los individuos y de los grupos sociales. La diversidad social dificulta el quehacer administrativo -máxime si se encuentran ubicados en sitios física y geográficamente diferentes-. 
Estas circunstancias son la que precisamente deben tenerse en cuenta para el diseño de políticas de gestión del recurso humano.

En Crepes \& Waffles se observa con claridad que la cantidad de empleados y la ubicación geográfica de los mismos en cada una de las sucursales no limita la comunicación directa diaria de su gerente con sus trabajadoras. De lunes a viernes, a las 11:45 a.m., por alta voz se dirige a todos sus empleados de la fábrica de alimentos, de los restaurantes y del área administrativa y les lee algunas líneas que contienen pensamientos e historias con el fin de estimular una reflexión acerca del amor, la paz, la armonía y la felicidad.

La gestión de esta importante empresa líder en el mercado nacional e internacional en el sector de las comidas y restaurantes demuestra la importancia de poner en práctica formas diferentes de administración del talento humano.

El sistema de comunicación implantado por Crepes \& Waffles con todos sus trabajadores presenta unas ventajas evidentes: ahorro en gastos y en tiempo, ya que mejora la comunicación con personas ubicadas en sucursales geográficamente dispersas; además refuerza continuamente el nivel de compromiso por la labor realizada.
Beatriz Fernández es un ejemplo de empresaria que cuenta con gran orientación y habilidad humana, que manifiesta en su labor un gran espíritu de confianza, entusiasmo y compromiso genuino en las relaciones con sus empleados. Manifiesta la capacidad no solo de conocerse a sí misma como ser humano sino que además transmite una fuerte simpatía. Es una convencida de la necesidad del desarrollo espiritual de la empresa para lograr su posicionamiento en el mundo de los negocios.

La filosofía del amor que sustenta la gestión gerencial en Crepes \& Waffles incide en todos los elementos de la cultura organizacional. Una de las estrofas del himno de la empresa contiene el siguiente mensaje: "Hay que contagiar a Colombia entera, por su libertad ${ }^{3}$. La guerra pa' fuera. Pon el corazón y fe a nuestra empresa, que es un don de Dios puesto en nuestra tierra.»

Estamos, en suma, frente a una empresa que muestra que si la apatía y la indiferencia pueden acabar con las organizaciones, las ideas y la conciencia construyen y trascienden: esta es la receta del éxito en Crepes \& Waffles 


\section{PAUTAS PARA LA PRESENTACIÓN DE ARTÍCULOS DESTINADOS A LA REVISTA INSTITUCIONAL DE LA ESCUELA DE ADMINISTRACIÓN DE NEGOCIOS EAN BOGOTÁ COLOMBIA}

\section{Elementos que debe incluir el artículo}

- Resumen en español y en inglés en el que se expliquen los objetivos específicos y las principales conclusiones del trabajo.

- Palabras claves en español y en inglés.

- Conclusiones o recomendaciones.

- Resumen de hoja de vida en máximo un párrafo, de cada uno de los autores.

- Datos de contacto de todos los autores. (email).

- Carta de autorización de la publicación del artículo, según el formato adjunto. En el caso de autores extranjeros o de otras ciudades, deben enviar el documento escaneado y deben observarse claramente las firmas de los mismos.

\section{Formato}

- Hojas tamaño carta $(21,5 \times 28 \mathrm{~cm}$. $)$.

- Textos escritos en letra Arial 12, en procesador word.

- Espacio doble.

- Extensión mínima 15 cuartillas y máxima 35.

\section{Normas de presentación}

\section{ICONTEC.}

- Notas de pie de página breves con numeración correlativa al texto, pautas de citación correcta y completa bibliografía utilizada para la elaboración del escrito, ordenada alfabéticamente (Protocolo Harvard).

- Codificar figuras, tablas estadísticas, cuadros y gráficos de tal manera que al hacer mención de estos dentro del texto, la relación entre el escrito y el respectivo esquema sea coherente. Los dibujos, gráficos y curvas deben remitirse en tinta negra y en procesador de texto o en paquetes de diseño gráfico.

- Concordancia entre los acápites, los textos y los cuadros, tablas, datos y figuras explicativas, adjuntando las series o variables, lo mismo que las notas de pie de página aclarativas, que deben observar la foliación. 
- Utilizar un sistema de nomenclatura que facilite la comprensión del texto.

Nota. Los trabajos presentados suponen que el material es original del autor y no ha sido publicado anteriormente o sometido simultáneamente a otra publicación.

\section{Naturaleza de los artículos}

Teniendo en cuenta que los artículos deben tener un carácter técnico, científico y cultural, el autor del texto puede considerar todos los temas; pero se dará prioridad a los artículos afines a las disciplinas del conocimiento a partir de las cuales la EAN genera sus programas de pregrado y postgrado y sus líneas de investigación.

Los artículos podrán ser resultados de investigaciones, estudios de casos, análisis teóricos donde se evidencien claramente los aportes analíticos del autos, etc.

\section{Sobre los derechos de autor}

- Los autores de artículos que se publiquen en la Revista, tendrán derecho a recibir 10 ejemplares del número de la edición en la que apareció la colaboración. El autor deberá autorizar a la EAN de manera escrita la publicación de su artículo.

- Los artículos publicados en la Revista de la EAN pueden ser reproducidos con fines académicos citando la fuente y el autor.

- Una vez aceptado un artículo para su publicación, el autor o autores transferirán los derechos a la Escuela de Administración de Negocios EAN por medio de la firma de un Acta de sesión de derechos, de acuerdo con lo estipulado por la Dirección Nacional de Derechos de Autor de Colombia.

- En cualquier caso, el Comité Científico y Editorial de la Revista entiende que las opiniones vertidas por los autores son de su exclusiva responsabilidad.

\section{PASOS PARA LA EDICIÓN DE LA REVISTA}

- El editor recibe los artículos y los somete al Comité Editorial de la Revista.

- Los artículos seleccionados por el Comité Editorial serán evaluados por pares (evaluación doblemente ciega) externos quienes emitirán un concepto sobre la eventual publicación del artículo.

- La Escuela de Administración de Negocios EAN se reserva el derecho de publicar o extractar los artículos y no se responsabiliza por el contenido de los mismos. 
